\section{Twenty-point plan for science policy}

The Brussels Declaration will be published at next month's meeting of the American Association for the Advancement of Science in Boston, Massachusetts. It is a 20-point blueprint for a set of ethics and principles to inform work at the boundaries of science, society and policy. It makes the case for a multidisciplinary approach that will encourage greater integrity and accountability among stakeholders.

The document brings together findings from a series of five consultation events and symposia at global conferences in 2012-16, in which more than 300 individuals from 35 countries examined the science of science policymaking. Using a grass-roots approach involving politicians, science advisers, scientific officers from industry, civil-society leaders, clinicians, social scientists, academia and science editors, the aim was to boost understanding of how power operates in science and society and to explain why evidence plus dialogue rarely equals good decisions and laws.

Most policy decisions are informed by evidence that is provided by experts. All too often, who those experts are, how they are chosen and the true reliability of their advice is open to question. Key requirements for public dialogue and better understanding are transparency, scrutiny and inclusivity.

We offer the Declaration for public comment (www.sci-com. eu) as an attempt to provide guidelines for incorporating scientific progress into the policymaking that affects all areas of our lives. It is in all our interests that we benefit from evidencebased policymaking rather than suffer policy-biased evidence. Michel Kazatchkine Office of the UN Special Envoy on HIV/AIDS, Geneva, Switzerland.

Julian Kinderlerer Cape Town University, South Africa.

Aidan Gilligan SciCom - Making
Sense of Science, Brussels, Belgium. ag@sci-com.eu

\section{Anthropocene: its stratigraphic basis}

As officers of the Anthropocene Working Group (AWG; J.Z. and C.W.) and chair of the Subcommission on Quaternary Stratigraphy (SQS; M.J.H.) of the International Commission on Stratigraphy (ICS), we note that the AWG has less power than Erle Ellis and colleagues imply (Nature 540, 192-193; 2016).

Its role is merely advisory - to evaluate the Anthropocene as a formal unit in the geological timescale. Proposals must pass scrutiny by the AWG, the SQS and the ICS before being ratified by the Executive Committee of the International Union of Geological Sciences.

The geological Anthropocene is not defined by holistic analysis of all human impacts on Earth, but by whether those impacts have produced suitable signals in the stratal record. Requirements include uniqueness, global extent, preservation potential and a synchronous base. A putative geological Anthropocene epoch would be nested within the Quaternary period, Cenozoic era and Phanerozoic eon. Myriad near-synchronous geological signatures in the stratigraphic record place its logical beginning in the mid-twentieth century, during the 'Great Acceleration' that marked a global increase in population, industrial activity and energy use.

The 'anthropogenic' epoch of Ellis et al. is different, and obscures this major Earth system and stratigraphic change. By including all human impacts across the world over millennia, their Anthropocene extends diachronously through the Late Pleistocene and Holocene to the present day. This overlap makes it meaningless as a geological timescale unit. The rich archaeological record, furthermore, is a characteristic of the Holocene epoch.

The AWG is interdisciplinary, with representatives from geology, archaeology, history, soil science, ecology, oceanography, polar science, atmospheric chemistry and international law. It works with physical scientists, social scientists, humanists and artists. It publicizes its activities through open meetings and peer-reviewed literature, and invites feedback. Ongoing work to conceptualize the geological Anthropocene must nonetheless remain within the ICS mandate. Jan Zalasiewicz University of Leicester, UK.

Colin Waters British Geological Survey, Keyworth, UK.

Martin J. Head Brock University, St Catharines, Ontario, Canada. cnw@bgs.ac.uk

\section{Anthropocene: social science misconstrued}

Adding in a wider range of socialscience expertise will not, in my view, help efforts to 'formalize the Anthropocene' as a geological age of human influence (E. Ellis et al. Nature 540, 192-193; 2016). The authors rightly want to expand the knowledge base involved in these efforts beyond stratigraphy and the Anthropocene Working Group, but their mistake is to assume that there can be agreed criteria - beyond 'golden spikes' and standard stratigraphic ages that will allow new international bodies to determine how and when to make the epoch 'official'.

Social science shows that the way people perceive and react to environmental and social change is both varied and contingent. It can elucidate the value judgements in most things that people do, including by experts across all fields. Through research, we can determine why, how and to what degree human activity is changing our planet. But in my view, it is folly to believe that there is an objective way to define a new 'age of humans'.

What counts as epochal change is a matter of perspective and emerges from judgements about when quantitative change morphs into qualitative transformation. The interpretive and critical parts of social science can help us to appreciate that formalizing the Anthropocene is a misguided attempt to 'scientize' a particular set of value judgements. No such formalization is needed to underpin arguments for humans to live in ways that are less environmentally destructive. Noel Castree University of Wollongong, Australia. ncastree@uow.edu.au

\section{Beware scientists wielding red pens}

By inviting scientists to take their 'red pens to the Internet' and grade online sources of science reporting, Phil Williamson implies that science is the primary and final voice in public discussion (Nature 540, 171; 2016). This disregards other ways in which people make sense of their lives through political debate, social context, personal connections or beliefs (see also D. Sarewitz Nature 522, 413-414; 2015). It stems from the naive myth of science as a disinterested producer of neutral truths.

Science has a delicate relationship with society. Both have the right to speak and both shape one another - for better or worse. Governance and government rely increasingly on a science that is embedded in socio-political arenas populated by scientists, policymakers and citizens, among others. Not every expertise is equally credible, but a democratic society should allow each one to have a voice.

To discredit them online may feel like defending the honour and public status of science, but it is a form of censorship. Science cannot impose its truths through power play - it must convince through symmetrical and open conversation.

Bart Penders Maastricht University, the Netherlands. b.penders@maastrichtuniversity.nl 